International Journal of Instrumentation and Control Systems (IJICS) Vol.4, No.2, April 2014

\title{
IMPORTANCE OF THREE-ELEMENTS BOILER DRUM LEVEL CONTROL AND ITS INSTALLATION IN POWER PLANT
}

\author{
Sanjoy Kumar Chakraborty ${ }^{1}$, Nilotpal Manna ${ }^{2}$ and Surodh Dey ${ }^{3}$ \\ ${ }^{1}$ Department of Electronics and Instrumentation Engineering \\ JIS College of Engineering, Kalyani, Nadia - 741235, India \\ ${ }^{2}$ HOD, Department of Electronics and Instrumentation Engineering \\ JIS College of Engineering, Kalyani, Nadia - 741235, India \\ ${ }^{3}$ Sr. Manager (INST), Tata Power Co. Ltd., Jamshedpur, India
}

\begin{abstract}
Conversion of water into steam is the primary function of a utility boiler. The steam pressure is used to turn a steam turbine thus, generating electricity. Within the boiler drum there exists a steam/water interface. Boiler steam drum water level is one of the important parameters of power plant that must be measured and controlled. For safe and efficient boiler operation, a constant level of water in the boiler drum is required to be maintained. Too low water level may cause damage boiler tube by overheating. On the other hand too high drum water level leads to improper function of separators, difficulty in temperature controlling and damage in superheater tubes. Turbine may also be damaged by moisture or water treatment chemicals carryover. The amount of water entering the boiler drum must be balanced with the amounts of steam leaving to accomplish the constant water level in the drum. Therefore it is extremely important to have the knowledge of the operating principles, installation requirements, strength and weaknesses of drum water level control system. Ignoring these considerations can result in misapplication, frequent maintenance, unsafe operation and poor instrument as well as system performance. In this paper design aspects and installation requirements of boiler drum level control are discussed for safe and economic operation.
\end{abstract}

\section{KEYWORDS}

Superheater, Steam Drum Level, Wet Leg System, Swell, Cascade Controller.

\section{INTRODUCTION}

Control of the proper water level in the boiler is critical for operation of the boiler. If the level is too low, boiler tube will be damaged by overheating. Too high water level leads to improper function of steam separators, difficulties in temperature control, and the moisture or water treatment chemical carryover can damage the super heater tubes and turbines. In addition, the drum pressure control is adversely affected by poor level control. Dynamic simulation studies of boiler conforms that internal parameters, such as steam pressure, drum level and steam temperature are essential to be within safety limits $[1,2]$. The sliding operation pressure of modern three drum Heat Recovery Steam Generators, along with frequent start up and shut down, contributes additional challenge of selecting the proper combination of instruments and maintaining correct water levels under all conditions.

Steam Drum Level is both critical and difficult to measure and maintain. Precise control of the water level in the drum is essential. Too high water level can result in water carryover into the DOI : $10.5121 /$ ijics.2014.4201 
steam piping. On the other hand, too low water level can expose the generating tubes (down comers), preventing the water in the drum from cooling the furnace tubes that may be the cause of possible damage. For measurement of drum level following points must be taken care of.

* Elimination of errors which are attributed in measurement due to fluctuating water level or changing rate of water inflow and steam outflow.

* Thermodynamics of pressure and temperature, geometry of the steam drum, and equation of continuity are the parameters to define transmitter calibration.

* The zero elevation and span against transmitter specifications must be checked to ensure proper calibration of selected transmitter.

Steam drum level controllers are being used from a very long period and their performance criteria are influenced by various constrains pertaining to control system, process dynamics \& mechanical structural design [3]. The fluctuation range of the water level and water supply flow can be effectively reduced by conventional PID controller with biological immune adjustment principle. It exhibits fast response and small overshoots characteristics [4]. The system performance can be enhanced by using fuzzy logic blocks to provide set-points for the system. Fuzzy supervisory control generates set-points for the conventional controllers using the strategy of fuzzy logic controllers (FLCs) [5].

Economic feasibility of a power plant requires smooth and uninterrupted plant operation in spite of varying electrical power demand. It has been observed from operation experiences of a power plant that one of frequent causes of shutdowns is by violation of safety limits on the water level and it is the common observance when the plant is at low operating power. PID controllers can handle most problems. However, these controllers may not work under certain conditions of operation such as the effects of "false water level" and wave action (wild oscillation of water surface). Adaptive Optimal control (AOC) is an important approach for dealing with nonlinearity problem [6], The concept of modular advanced control system designed for a seamless and gradual integration into the existing distributed control system has been investigated [7]. For the quadruple tank process, combination of a gain scheduling controller, a linear parameter varying controller and an input-output feedback linearization controller have demonstrated very good performance [8].

The Steam Drum level control is also an influencing factor of overall safety of the power plant as it is closely related to Main Heat Transport coolant inventory and sustained heat removal through natural circulation. Steam drum level control at multiple loop configurations has been proposed to enhance the safety margin $[9,10]$. For proper control of drum level single parameter control is not sufficient, and three element Steam Drum Level Controller has been conventionally used for most of the boilers where controlling parameters are Drum level, steam flow and feed water flow. In this paper we will discuss on some the critical issues on drum level measurement and control, design aspects and installation requirements for safe and trouble-free operation.

\section{MEASUREMENT TECHNIQUES OF DRUM LEVEL}

Precise measurement of drum level is very difficult due to several factors.

* The steam drum itself may not be at perfectly level.

* Even at steady state conditions, considerable turbulence in the drum can cause the level to fluctuate.

* Changing rate of water inflow and steam outflow adds to the potential for measurement error. 
Measurement of boiler steam drum level using differential pressure transmitter must take into account of certain physical properties of the fluid.

* The steam drum contains a two-phase mixture of water and steam at saturation condition.

* The densities of water and steam vary with saturation temperature and pressure.

* The density of saturated steam above water must be considered, as well as the density of saturated water in the drum.

There exist several instruments which provide for determination of the boiler drum level by direct observation such as gauge glasses. This device provides the direct viewing of the liquid level. Various designs are available providing reflex, transparent or refraction (Bi-colour) images. However for accurate measurement of drum level and transmit to various equipments for processing differential pressure transmitter is used.

\subsection{Gauge Glass}

It is the transparent tube may be mostly enclosed within a metal or toughened glass shroud is mounted on boiler for direct indication of water level. Two issues are essential in selecting gauge glasses. Firstly, the ASME (American Society of Mechanical Engineers) Code requires each fired boiler to have gauge glass and secondly gauge glasses for all boilers operating above 400 PSI. The gauge glasses must be visible to the boiler operator at the location where immediate control action is initiated.

\subsection{Electronic Probe Level Sensors}

Increasingly popular for remote level indication is use of probe type level indicators. The device consists of an array of probes that provide an incremental representation of the level. These probes monitor the presence of water electrically and provide both an indication of the level and control contacts. This eliminates the need for separate devices for indication and control.

\subsection{Wet Leg System}

For precise measurement of drum level Wet Leg System is useful. In a wet leg system, differential pressure transmitter is used where the low pressure impulse line is completely field with liquid (usually the same liquid as the process), and hence the name wet leg. The schematic diagram of wet leg system is presented at figure1. 


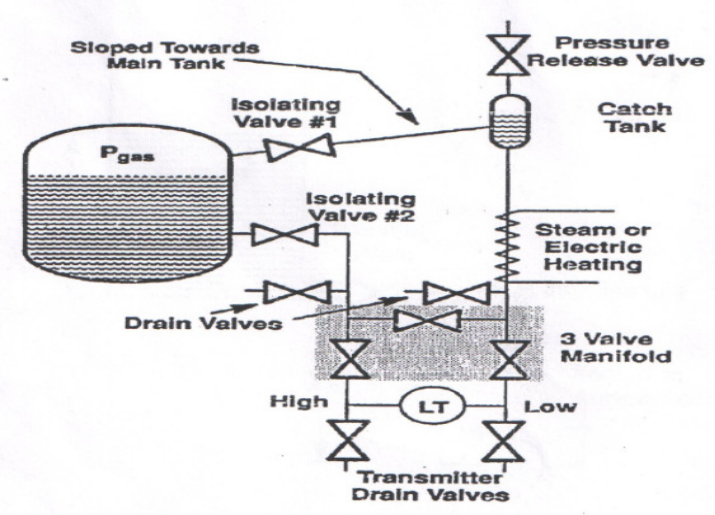

Figure 1: A wet leg installation

A level transmitter (LT), in association with three valves manifold, is used in an identical manner as the dry leg system. The gas phase or vapour will be condensed in the wet leg and the catch tank. The catch tank, with the inclined interconnection line, maintains a constant hydrostatic pressure on the low pressure side of the level transmitter. This pressure, being a constant, can easily be compensated for by calibration. Depending on the installation technique and position of level transmitter in respect of boiler drum, it is necessary to introduce offset at time of calibration of transmitter. Two approaches are explained here with mathematical interpretation.

(a) Zero Suppression: In some cases, the level transmitter has to be mounted $\mathrm{X}$ meters below the base of an open tank as shown in figure 2.

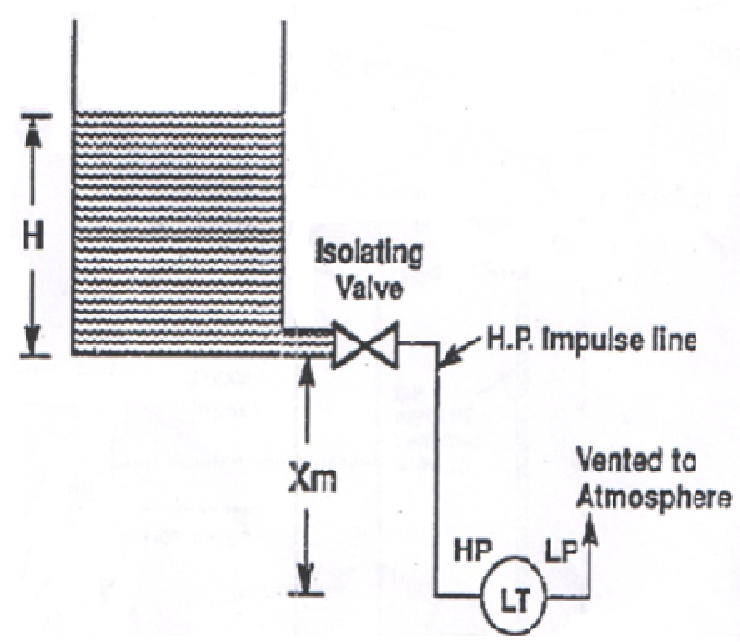

Figure 2: Level transmitter with zero suppression

The liquid in the high pressure impulse line exerts a constant pressure $(P=S . X)$ on the high pressure side. $S$ is the constant applied for Pressure to height relation. When the liquid level is at $\mathrm{H}$ meters, pressure on the high pressure side of the transmitter will be:

$$
\begin{aligned}
& P_{\text {High }}=S . H+S . X+P_{A t m} \\
& P_{\text {Low }}=P_{\text {Atm }}
\end{aligned}
$$




$$
P_{\text {Diff }}=P_{\text {High }}-P_{\text {Low }}=S . H+S . X
$$

The transmitter has to be negatively biased by a value of $(-S . X)$ so that the output of the transmitter is proportional to tank level $(S . H)$ only. The above procedure is called zero suppression and it can be done during calibration of the transmitter.

(b) Zero Elevation: When the height of the wet leg $(\mathrm{X})$ is equal to or greater than the maximum height of the liquid column $(\mathrm{H})$ inside the tank as shown at figure 3, zero elevation offset is to be applied while calibration of level transmitter.

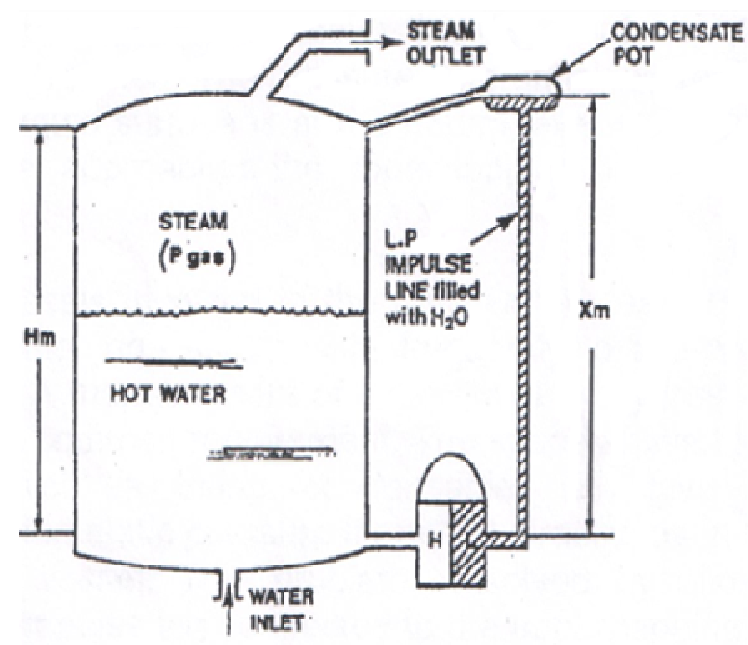

Figure 3: Wet Leg installation with zero elevation

In a wet leg installation the low pressure side of the level transmitter will always experience a higher pressure than the high pressure side. When the liquid level is at $\mathrm{H}$ meters, we have:

$$
\begin{aligned}
& P_{- \text {High }}=P_{- \text {gas }}+S . H \\
& P_{\perp \text { Low }}=P_{- \text {gas }}+S . X \\
& P_{\_ \text {Diff }}=P_{- \text {High }}-P_{- \text {Low }}=S . H-S . X=-S(X-H)
\end{aligned}
$$

The differential pressure $\mathrm{P}_{\text {Diff }}$ sensed by the transmitter is always a negative number (i.e. low pressure side is at a higher pressure than high pressure side). For proper calibration of the transmitter, a positive bias $(S . X)$ is introduced to elevate the transmitter output. The positive biasing technique is called zero elevation.

\section{BOILER DRUM LEVEL MEASUREMENT}

Drum water level is better measured by differential pressure transmitter. In a pressurized vessel, measurement of differential pressure is based on the phenomenon that the pressure exerted at any depth below the surface of the liquid is equivalent to the sum of the hydrostatic pressure acting at the point of measurement and the static pressure acting on the surface of the liquid. The hydrostatic pressure can be estimated by multiplying distance of the measuring point below the liquid surface with liquid density. It is illustrated by the schematic diagram at figure 4 . 


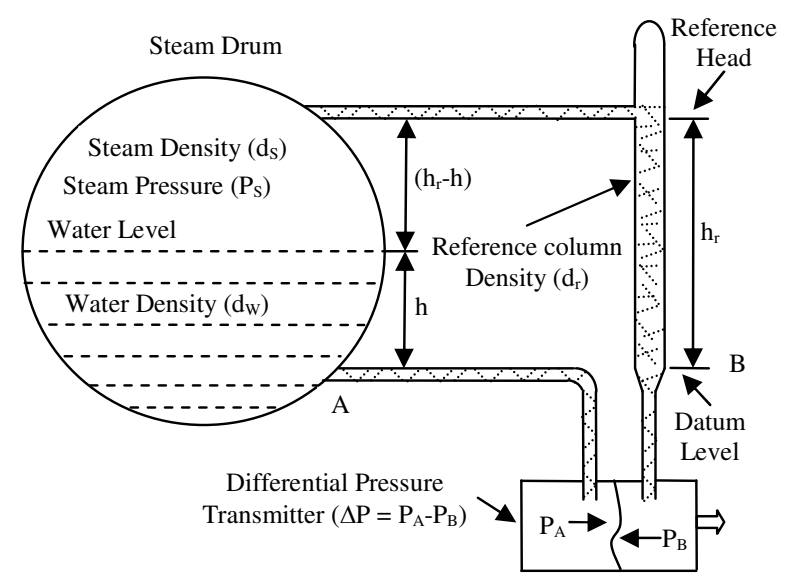

Figure 4: Water level measurement in a pressure vessel

For example, a vessel is pressurized by the steam pressure $P_{S}$ acting on the surface of water of density $\mathrm{d}_{\mathrm{W}}$, the level of the liquid being represented by $\mathrm{h}$, above a datum point. Pressure-sensing connections are provided at the datum (A) and to the gas space (B). The pressure sensed at A is due to the column of hot water $(h)$, above the datum, in addition to the static pressure $\left(P_{S}\right)$, acting on the liquid surface and drum steam pressure $\left(P_{0}\right)$. The pressure sensed at B is only the static pressure $\left(P_{S}\right)$. Hence the difference between two pressures $P_{\text {Diff }}$ will be equivalent to the hydrostatic head of the water level above the datum. By locating the pressure tapping points to give a desired range of level measurement and measuring the pressure differential between them, the liquid above the datum at any point within the range may be determined.

The pressure differential will reach its maximum value when the liquid surface is at the datum level, and approaches towards zero when the liquid level reaches to the upper tapping point, thus governing the maximum level range.

The hydrostatic pressure is due to the height of the water level above the datum. Representing the height of the surface above the datum as $h$ and the density of the water at drum pressure and saturation temperature as $d_{W}$, the hydrostatic pressure due to water column $\left(P_{W}\right)$ will be given by:

$$
P_{W}=h d_{W} g
$$

The pressure of a column of steam is acting on the water surface. The height of the column of steam will be the difference between overall ranges. Thus represents the operating range of the level measurement. If $h_{r}$ is been made equivalent to the height of the constant condensate column, and the density of the drum steam pressure as $d s$, the pressure $\left(P_{S}\right)$ acting on the surface of the water is given by:

$$
P_{S}=\left(h_{r}-h\right) d_{S} g
$$

The pressure due to the constant condensate column is:

$$
P_{r}=h_{r} d_{r} g
$$

When the drum steam pressure is $P_{0}$, the total pressure at $\mathrm{A}$ is equivalent to: 
International Journal of Instrumentation and Control Systems (IJICS) Vol.4, No.2, April 2014

$$
\begin{aligned}
& P_{A}=P_{W}+P_{S}+P_{0} \\
& =h d_{W} g+\left(h_{r}-h\right) d_{S} g+P_{0}
\end{aligned}
$$

Similarly, total pressure measured at B is:

$$
\begin{aligned}
P_{B} & =P_{r}+P_{0} \\
& =h_{r} d_{r} g+P_{0}
\end{aligned}
$$

Therefore $P_{\text {Diff }}=P_{A}-P_{B}$

$$
\begin{gathered}
=h d_{W} g+\left(h_{r}-h\right) d_{S} g+P_{0}-h_{r} d_{r} g-P_{0} \\
=h d_{W} g+\left(h_{r}-h\right) d_{S} g-h_{r} d_{r} g \\
=h\left(d_{W}-d_{S}\right) g-h_{r}\left(d_{r}-d_{S}\right) g
\end{gathered}
$$

Thus above equation clearly shows that differential pressure is linearly equivalent to water level of the drum if other parameters are constant. However the accuracy of the method of level measurement as described will be significantly degraded if the following practical design conditions are not met.

* The temperature of the condensate in the reference column must be as closed as possible to the water in the vessel.

* The pressure in the vessel must not deviate significantly from the working pressure for which the applied values of the densities of the water and steam are taken.

- The reference column head must remain constant and stable under all operating conditions during which the level measurement is required.

* The two impulse lines from the plant tapings to the differential pressure transmitter must originate from plant connections at the same level, be geometrically similar and be maintained, as near as possible, at the same temperature.

\section{BOILER DRUM LEVEL CONTROL}

The information on boiler drum level as measured by above procedure is fed to various process control units, DCS, SCADA etc. for analysis. After analyzing various information from the drum level system and other associated sub-systems, the actuating signals are generated from control units to actuate the control valves of boiler feed water inlet as well as outlet and steam outlet, to make them open or close.

Under boiling condition, steam supporting field products such as bubbles exist below the water/steam level interface. There bubbles have volume and therefore displace water to create a misrepresentation of the true water level in the drum.

Pressure in the drum has another effect upon drum level. Steam bubbles are compressed under pressure. Due to varying demands of load, the drum pressure changes and therefore the steam bubbles expand or contract respective to these pressure changes. A higher steam demands will cause the drum pressure to drop, and the steam bubbles to expand to give the appearance of a water level that it truly is. The fictitious higher water level cause the feed water input to be shut down at a time when more water is really required. A surge in water level as a result of the drum pressure decreasing is called swell. A water level decrease due to drum pressure increase is called shrink.

\subsection{Single Element Drum Level Control}

The level transmitters are used to measure the actual drum level. The average of these transmitter output are compensated for the drum pressure. For load less than $30 \%$, this measured level is 
compared with the set value and the error (single element level error) is applied to the controller for positioning the control valve at no load (0-30) \% capacity. The control valve position signal is used as negative feedback for improving the response of the control system.

During start of a boiler, both the feed water and main steam flow rates are below the measurable ranges, and therefore the three-element control with a level controller and flow controller results unstabilty. In such cases, it is effective to use single element control in which the feed water controller is bypassed and the drum level controller directly controls the feed water control valve. However Single Element Drum Level Control does not perform properly once the boiler is fully operative. For full running condition of boiler unit other parameters must be taken into account. In this case three elements drum level control is most effective.

\subsection{Three -Elements Drum Level Control}

If an unstable feed water system exists exhibiting a variable feed header-to-drum pressure differential, or if large unpredictable steam demands are frequent, a three-elements drum level control scheme should be considered. Three elements control is used for load greater than $30 \%$, to take care of swelling and shrinking asset with load function at higher load.

The control is based on three parameters - mainly a) Drum level b) steam flow c) feed water flow. Errors of these three elements are computed and control signals are generated to position the selected full load control valves $(30 \%-100 \%)$.

* Drum Level is measured from drum level transmitter with the compensation of drum pressure.

* Feed Water Flow with compensation of pressure of feed water and temperature.

* Main Steam Flow with the help of pressure and temperature and temperature compensation.

This three-elements controller is often referred as cascade controller in which a drum level control unit is cascaded into a feed water flow control unit. A schematic diagram of Cascade controller or three elements drum level controller is shown at figure 5.

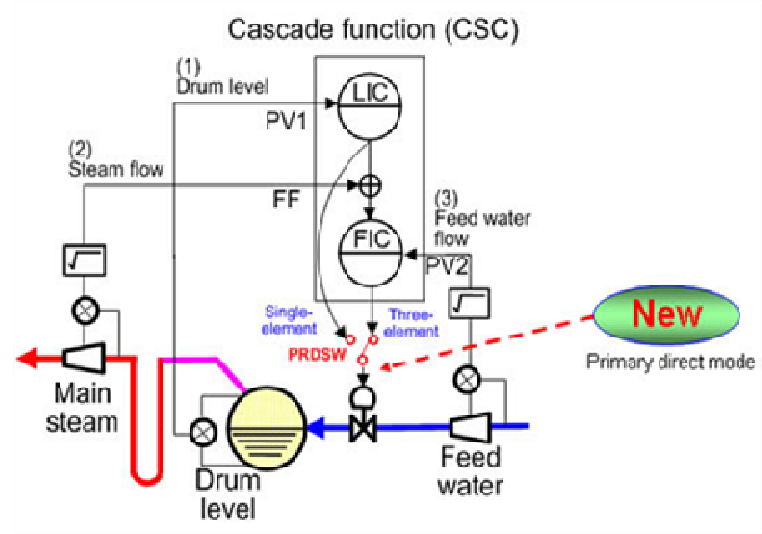

Figure 5: Three Elements Drum Level Control 
International Journal of Instrumentation and Control Systems (IJICS) Vol.4, No.2, April 2014

\section{INSTALLATION AND ERECTION WORK}

For precise controlling of the boiler drum level, the three elements control is most effective for considering other important parameters that govern the drum level. Therefore several instruments are to be installed. Differential Pressure Transmitters are used for measurement of level and flow. Two control valves are utilized as a final control element for controlling of water and steam flow. Level switches are used for indication and alarm to ensure the safety. Temperature transmitter are using for measurement of temperature. All these instruments must be of good accuracy and safe permissible limit to ensure safety and trouble free operation. The field equipments that are to be deployed are as under:

1. Differential Pressure for drum level - 2 nos.

2. Flow Transmitter for feed water control - 1 no.

3. Flow Transmitter for steam flow control - 1 no.

4. Pressure Transmitter for drum pressure measurement - 1 no.

5. Temperature Transmitter - 1 no.

6. Level Switches for steam drum water level indication with tripping signal: Very Low Indication, Low Indication, High Indication, Very High Indication

7. Control Valve for steam flow with positioner - 1 no.

8. Control Valve for water flow with positioner -1 no.

Minimum requirements of I/O cards in DCS for controlling the parameters and synchronous operation are as under:

Analog Input card (8 channel) - 1 No.

Analog Output card (4 channel) - 1 No.

Digital Input card, 24 V DC (16 channel) - 1 No.

Digital Output card, 24 V DC (16 channel) - 1 No.

\section{CONCLUSION}

By steam drum level control, fluctuating of water level or changing rate of water inflow and steam outflow can be controlled in a better way. The observation data of three elements boiler drum level control of a power plant on a particular day is presented here. These are tabulated at table 1 and computer display screen is shown at figure 6. Full Load Main CV (OP) represents main control valve output in \% for feed water flow to maintain steam drum water level. Full Load FW FCV (main) (PO) is the process value (PV) of feed water flow control valve. 3TX SEL Comp Drum Level (PV) is the process value in $\mathrm{mm}$ of level transmitter (average value of three transmitters) which is final control parameter. Feed Water Flow (PV) is the process value from feed water flow transmitter that is one of the input value to PID controller. Total steam flow (PV) is the process value from steam flow transmitter. Actual load (PV) is the plant capacity in \%. Here plant capacity is considered as $120 \mathrm{MW}$ and current values/ readings are shown at graph are taken at one hour interval. It may be observed that steam drum level is controlled in better way. The steam output is exactly according to the process requirement and thus overall efficiency is increased. 
International Journal of Instrumentation and Control Systems (IJICS) Vol.4, No.2, April 2014

\begin{tabular}{|c|c|c|c|c|c|c|}
\hline TIME & $\begin{array}{l}\text { FULL LOAD } \\
\text { MAIN CV } \\
\text { (OP) }\end{array}$ & $\begin{array}{l}\text { FULL LOAD } \\
\text { FW FCV } \\
\text { (MAIN) (PV) }\end{array}$ & $\begin{array}{l}\text { 3TXSEL } \\
\text { COMP } \\
\text { DRUM } \\
\text { LEVEL (PV) }\end{array}$ & $\begin{array}{l}\text { FEED } \\
\text { WATER } \\
\text { FLOW } \\
\text { (PV) }\end{array}$ & $\begin{array}{l}\text { TOTAL } \\
\text { STEAM } \\
\text { FLOW (PV) }\end{array}$ & $\begin{array}{l}\text { ACTUAL } \\
\text { LOAD (PV) }\end{array}$ \\
\hline & 1. $4 \mathrm{FW} 3 \mathrm{C} 31 . \mathrm{OP}$ & 2. 4P0X4227. PV & 3. 4FW1P07. PV & 4. 4FW2PO7. PV & 5. 48M1P04. PV & 6. 4NATO43. PV \\
\hline 11/7/2013 5:30:00 AM & 73.42 & 72.83 & 0.07 & 264.16 & 263.16 & 87.02 \\
\hline 11/7/2013 4:30:00 AM & 73.54 & 72.89 & 0.26 & 260.03 & 258.54 & 86.08 \\
\hline 11/7/2013 3:30:00 AM & 73.10 & 72.49 & 0.33 & 260.18 & 258.00 & 85.82 \\
\hline $11 / 7 / 20132: 30: 00 \mathrm{AM}$ & 73.29 & 72.75 & -0.62 & 261.67 & 258.18 & 85.81 \\
\hline 11/7/2013 1:30:00 AM & 73.31 & 72.73 & -0.51 & 259.53 & 256.65 & 85.19 \\
\hline $11 / 7 / 2013$ 12:30:00 AM & 73.21 & 72.60 & -0.82 & 257.86 & 256.06 & 85.04 \\
\hline 11/6/2013 11:30:00 PM & 73.86 & 73.24 & 1.04 & 268.06 & 268.58 & 89.25 \\
\hline 11/6/2013 10:30:00 PM & 74.29 & 73.70 & -0.24 & 275.96 & 273.55 & 90.63 \\
\hline 11/6/2013 9:30:00 PM & 77.07 & 76.56 & -0.53 & 331.10 & 328.95 & 109.37 \\
\hline $11 / 6 / 20138: 30: 00 \mathrm{PM}$ & 77.71 & 77.14 & -0.21 & 346.97 & 344.75 & 114.47 \\
\hline $11 / 6 / 20137: 30: 00 \mathrm{PM}$ & 78.15 & 77.54 & 0.20 & 351.75 & 349.92 & 116.33 \\
\hline $11 / 6 / 20136: 30: 00 \mathrm{PM}$ & 77.94 & 77.39 & 0.14 & 340.67 & 339.55 & 112.90 \\
\hline 11/6/2013 5:30:00 PM & 76.38 & 75.78 & -0.06 & 307.09 & 305.54 & 101.40 \\
\hline 11/6/2013 4:30:00 PM & 75.14 & 74.50 & 0.52 & 288.69 & 288.74 & 95.63 \\
\hline 11/6/2013 3:30:00 PM & 75.82 & 75.11 & 0.09 & 299.56 & 300.12 & 99.53 \\
\hline 11/6/2013 2:30:00 PM & 75.93 & 75.24 & -0.12 & 295.86 & 297.50 & 98.81 \\
\hline $11 / 6 / 2013$ 1:30:00 PM & 74.47 & 73.77 & -0.20 & 275.65 & 275.61 & 91.59 \\
\hline $11 / 6 / 2013$ 12:30:00 PM & 76.16 & 75.49 & -0.05 & 310.65 & 310.64 & 103.15 \\
\hline 11/6/2013 11:30:00 AM & 76.52 & 75.85 & -0.21 & 312.69 & 312.38 & 103.26 \\
\hline 11/6/2013 10:30:00 AM & 74.80 & 74.24 & 0.46 & 279.80 & 279.96 & 92.66 \\
\hline 11/6/2013 9:30:00 AM & 74.37 & 73.74 & 0.65 & 275.59 & 275.35 & 91.22 \\
\hline 11/6/2013 8:30:00 AM & 73.58 & 72.99 & 0.02 & 257.60 & 257.35 & 85.17 \\
\hline $11 / 6 / 2013$ 7:30:00 AM & 73.44 & 72.87 & -0.11 & 255.61 & 256.02 & 84.78 \\
\hline 11/6/2013 6:30:00 AM & 73.18 & 72.57 & 0.26 & 254.98 & 255.66 & 84.77 \\
\hline $11 / 6 / 20135: 30: 00 \mathrm{AM}$ & 73.21 & 72.61 & 0.08 & 255.08 & 255.48 & 84.70 \\
\hline
\end{tabular}

Table 1: Observations after installation

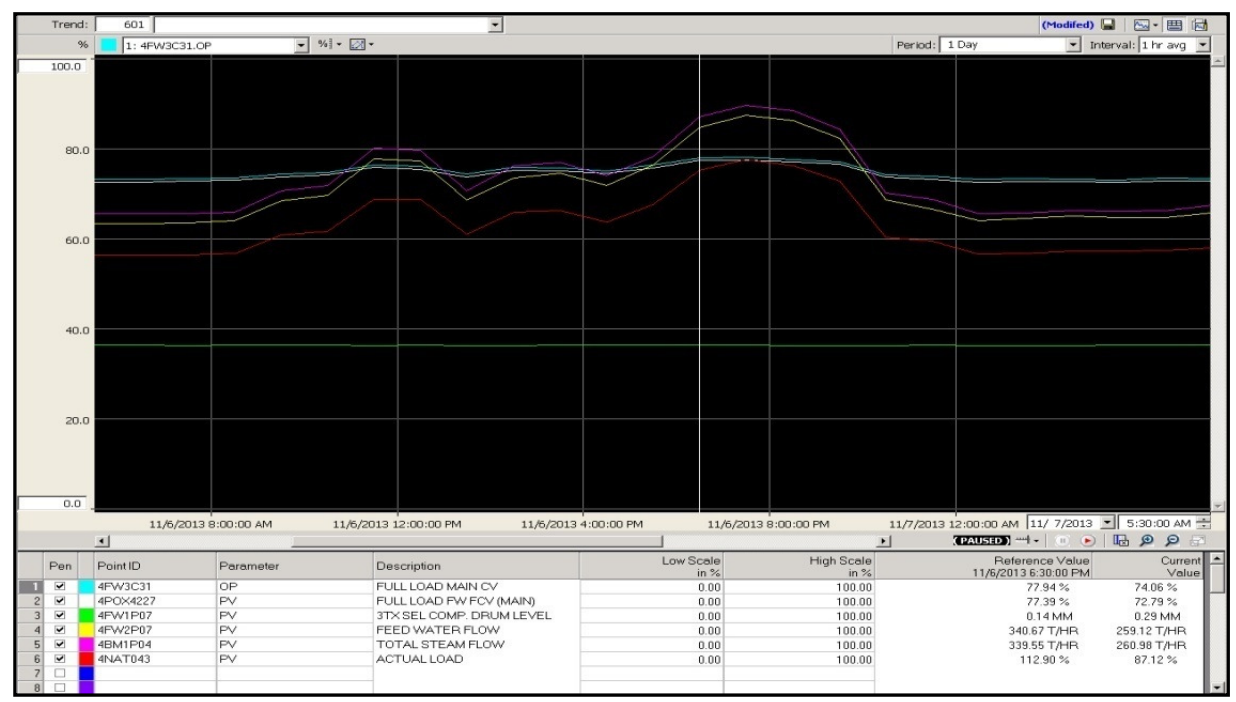

Figure 6: Control panel computer display

\section{ACKNOWLEDGEMENTS}

The Authors acknowledge the Technical Education Quality Improvement Program (TEQIP) for the support to precede the publication. 
International Journal of Instrumentation and Control Systems (IJICS) Vol.4, No.2, April 2014

\section{REFERENCES}

[1] M. E. Flynn and M. J. O\&\#39;Malley "A drum boiler model for long term power system dynamic simulation", IEEE Trans. Power Syst., vol. 14, no. 1, pp.209-217 1999.

[2] F. P. de Mello "Boiler models for system dynamic performance studies", IEEE Trans. Power Syst., vol. 14, no. 1, pp. $209-2171991$.

[3] Y. Huang\&\#39;1, N. Li2, Y. Shil and Y. Yil "Genetic adaptive control for drum level of a power plant boiler", Proc. IMACS Multiconf. Computat. Eng. Syst. Applicat. (CESA), vol. 2, pp.1965 19682006.

[4] Zhou Li, Sun Xia "The Study of Boiler Control System of Water Level of Steam Drum Based on New Immune PID Controller", Second International Conference on Digital Manufacturing and Automation (ICDMA), 2011 Page(s):1336 - 1339.

[5] E. Arriaga-de-Valle and G. Dieck-Assad "Modeling and simulation of a fuzzy supervisory controller for an industrial boiler", Simulation, vol. 82, no. 12, pp.841 -850 2006.

[6] Y. Nanhua , M. Wentong and S. Ming "Application of adaptive grey predictor based algorithm to boiler drum level control", Energy Conversion Manage. 47, pp.2999 -3007 2006.

[7] D. G. Andone , J. I. Fagarasan and M. R. Dobrescu "Advanced control of a steam generator", Proc. 3rd Int. IEEE Conf. Intell. Syst., pp.338 -343 2006.

[8] M. Mercang\&ouml;z and F. J. Doyle "Distributed model predictive control of an experimental fourtank system", J. Process Control 17, pp.297 -308 2007.

[9] A. J. Gaikwad , P. K. Vijayan , K. Iyer , S. Bhartiya , R. Kumar , H. G. Lele , A. K. Ghosh , H. S. Kushwaha and R. K. Sinha "Effect of loop configuration on steam drum level control for a multiple drum interconnected loops pressure tube type boiling water reactor", IEEE Trans. Nucl. Sci., vol. 56, no. 6, 2009.

[10] G. Y. Qiliang, X. Jianchun and W. Ping "Water level control of boiler drum using one IEC61131-3based DCS", Proc. 26th Chinese Control Conf., pp.252 -255 2007.

[11] W. Dong, J. M. Doster and C. W. Mayo "Steam generator control in nuclear power plants by water mass inventory", Nucl. Eng. Design 238, pp. 859 -871 2008.

[12] W. J. Peet and T. K. P. Leung "Improved drum level control for load cycling", Proc. IEEE 2nd Int. Conf. Adv. Power Syst. Control, Operat., Manage., vol. 1, pp.130 -134 1993.

[13] M. G. Na "Design of a genetic fuzzy controller for the nuclear steam generator water level control", IEEE Trans. Nucl. Sci., vol. 45, no. 4, pp.2261 -2271 1998.

[14] P. J. Campo and M. Morari "Model predictive optimal averaging level control", AIChE J., vol. 35, no. 4, pp. $579-5911989$.

[15] J. Balaram, C. N. Shen and R. T. Lahey Jr. "Muliltivariable stability margins for boiling water nuclear reactors", Proc. 21st IEEE Conf. Decision Control, vol. 21, pp. 1036 -1041 1982.

[16] D. H. Kim "Nuclear steam generator level control by a neural network-tuning 2-DOF PID controller", Proc. CIMSA 2004-Int. Symp. Comput. Intell. Meas. Applicat., pp.168 -173 2004.

[17] F. D\&\#39;Auria , B. Gabaraev , V. Radkevitch , A. Moskalev , E. Uspuras , A. Kaliatka , C. Parisi , M. Cherubini and F. Pierro "Thermal-hydraulic performance of primary system of RBMK in case of accidents", Nucl. Eng. Design 238, pp.904 -924 2008.

[18] A. Kaliatka, E. Urbonavicius and E. Uspuras "Approach to accident management in RBMK-1500", Nucl. Eng. Design 238, pp.241 -249 2008.

[19] H. Mochizuki, M. H. Koike and T. Sakai "Core coolability of an ATR by heavy water moderator in situations beyond design basis accidents", Nucl. Eng. Design 144, pp.293 -303 1993.

[20] S. Mita a , M. Akebi b , O. Sawamura a and T. Kondo "Development of the advanced thermal reactor in Japan", Nucl. Eng. Design 144, pp.283 -292 1993.

[21] F. D\&\#39;Auria , B. Gabaraev , V. Radkevitch , A. Moskalev , E. Uspuras , A. Kaliatka , C. Parisi , M. Cherubini and F. Pierro "Thermal-hydraulic performance of primary system of RBMK in case of accidents", Nucl. Eng. Design 238, pp.904 -924 2008. 


\section{ABOUT THE AUTHORS}

Sanjoy Kumar Chakraborty completed A.M.I.E. in Electronics \& communication engineering in the year of 1992 from the Institution Of Engineers (I).He is M .Tech student (final semester) of Applied Electronics \& Instrumentation from JIS college of engineering. He has been trained at various software courses from Jadavpur University including Information Technology from CMC. He has about 19 years experience in process control and instrumentation with exposure of project execution, erection \& commissioning and \& maintenance. The projects are related to steel plane, chemical plant, cement plant, oil industry etc. He worked in Ruchi Soya Industries Ltd. as Dy. Manager Instrumentation. He is the Member of Electronics \& Telecommunication engineering division \& computer science and engineering division of Institution of engineers (I), Kolkata chapter.

Nilotpal Manna obtained B.E. degree in Electronics and Telecommunication Engineering in 1979 from Bengal Engineering College, Sibpore, Kolkata, now renamed as Bengal Engineering and Science University and received M Tech degree in 1981from Indian Institute of Technology Madras (Chennai). He has wide industrial experience of twenty-two years from semi- government sectors like Instrumentation Ltd, Kota and several private industries like Toshniwal Instruments Manufacturing Pvt Ltd and others. He served mostly in the Research and Development wings and was associated in development of various electronic and communication instruments meant for military application as well as development of analytical instruments. At present he is Head of the Department of Electronics and Instrumentation Engineering of JIS College of Engineering, Kalyani, West Bengal, India. He has several research publications in national and international journals and conferences, and authored four technical books.

E-mail: nmanna324@gmail.com

Mr. Surodh dey completed A.M.I.E in electronics and communication engineering from the Institution of Engineers (I) in the year 1991. He joined Bells Control Ltd. as instrumentation engineer. Thereafter he joined Tata Honeywell Ltd (USA based company) at customer support division and worked for fourteen years. He was assigned to installation and erection work of various power projects. At present he is working in Tata Power Co Ltd. as head of the Instrumentation Department. 